\title{
Wastewater Treatment using a Biofilm Process for Greywater Reclamation and Reuse in Thailand
}

\author{
SUPATTRA JIAWKOK and JUN NAKAJIMA \\ Department of Environmental Systems Engineering, Ritsumeikan University \\ /1-1-1 Nojihigashi, Kusatsu, Shiga 525-8577, Japan
}

\begin{abstract}
To mitigate water shortage and pollution, decentralized reclamation and reuse of domestic greywater in peri-urban areas of Bangkok, Thailand was proposed. The treatability of greywater using a biofilm process was discussed using laboratory scale experiments with and without aeration and different HRT. The removal of anion surfactants (MBAS) as well as linear alkyl benzene sulfonate (LAS) was greater than $\mathbf{9 0 \%}$ in the oxic experiments, even with an HRT of 1 day. The removal rates were much lower during the anoxic experiments. The MBAS removal by the sludge accumulation, estimated by measuring the sludge production rate, was trivial. Therefore, it was suggested that the removal of MBAS was primarily a result of biological degradation. A decrease in phosphorus addition in detergent is recommended because the poly-P in detergents can be hydrolyzed during the treatment process and would cause eutrophication. The contact aeration process appeared to be applicable to greywater reclamation and reuse in the periurban area of Bangkok.
\end{abstract}

Keywords: Greywater treatment, water reclamation and reuse, peri-urban area, detergent removal, polyphosphate

\section{INTRODUCTION}

Southeast Asian megacities have been rapidly growing and progressively increasing industrialization and urbanization in their peri-urban areas. Delays in developing infrastructure and a lack of effective planning for wastewater management have caused water shortages, scarce water resources and water pollution ${ }^{1)}$. To mitigate such water shortage and pollution, the authors have considered decentralized reclamation and reuse of domestic wastewater in peri-urban areas of Bangkok, Thailand.

In Thailand, blackwater is usually treated in septic tanks, based on the regulation that shows installation of treatment systems to minimize the pollution into the environment ${ }^{2}$. Consequently most of blackwater (toilet wastewater) is disposed into the septic tank before being discharged into the environment, while the greywater from the kitchen, laundry washing and bathroom is improperly disposed. The discharge of untreated greywater has contributed to water pollution in many canals and rivers across Thailand. The environmental pollution by greywater is similar to the urban river pollution caused by untreated domestic wastewater in Japan during the 1970s-1980s. The Johkasou (a combined type of treatment system) as well as sewage systems have been successfully introduced to treat a mixture of greywater and black water to control the pollution ${ }^{3)}$. However, the authors are studying alternative solutions that can be employed for decentralized water reuse in Thailand.

According to our recent questionnaire 
survey performed in Khlong Luang and Khlong Jik, a peri-urban area of Bangkok in 2010 , more than $80 \%$ of households responded to accept the reuse of treated greywater for gardening, car washing or floor cleaning, although approximately 50\% of households reported that they would not accept treated water that contained black water for reuse ${ }^{4)}$. Because the BOD concentration and pathogenic risks of greywater alone are lower than combined wastewater containing black water, greywater reclamation and reuse can be considered as an appropriate application for a decentralized system in the area.

The biofilm process is a potential treatment system to reduce the pollutant load of greywater ${ }^{5}$. It is widely used in Japanese johkasou as a contact aeration process that is easy to operate and maintain. Package type septic tanks using anaerobic biofilm processes have been manufactured and provided by Thailand companies for small-scale treatment of black water ${ }^{6,7}$. Moreover, the companies have begun to manufacture tanks with biofilm processes with aeration ${ }^{6,7)}$. Therefore, the biofilm process both with and without aeration would be easily employed for greywater reclamation and reuse in Thailand, compared with more advanced treatment processes.

The previous survey ${ }^{4)}$ also showed that greywater was rich in anionic surfactants, such as methylene blue active substances (MBAS) and polyphosphate (poly-P) content, that originated from detergents. The surfactants cause foaming in natural water sources, where the effluent wastewater is disposed $^{8)}$ and cause toxicity to aquatic organisms ${ }^{9}$. The most widely used anionic surfactants for manufacturing detergents were linear alkylbenzene sulfonate (LAS) with alkyl chains ranging from $\mathrm{C}_{10}$ to $\mathrm{C}_{14}$ and sodium dodecyl sulfate (SDS) ${ }^{10,11}$. The toxicity of the LAS compounds increases as the number of carbon atoms increases ${ }^{12}$. It has been reported that municipal wastewater contained more than $1 \mathrm{mg} / l$ of LAS with alkyl chain lengths from $\mathrm{C}_{10}$ to $\mathrm{C}_{13}{ }^{13)}$. Although LAS degrades more easily in the environment compared to hard type alkylbenzene sulfonate $(\mathrm{ABS})^{8}$, the residual LAS was detected more than $80 \%$ of MBAS in river waters ${ }^{14)}$.
Some detergents contain tripolyphosphate salts to reduce minerals in water $\left(\mathrm{Mg}^{2+}\right.$ and $\mathrm{Ca}^{2+}$ ) that contribute to water "hardness." These minerals can react with surfactants and decrease the detergent capacity ${ }^{15)}$. Poly-P in detergents is known to be hydrolyzed to phosphate phosphorus $\left(\mathrm{PO}_{4}-\mathrm{P}\right)$ and cause eutrophication in aquatic systems ${ }^{16)}$. Although phosphate-free detergents had been introduced in Japan in the $1980 \mathrm{~s}$, some detergents containing poly- $\mathrm{P}$ are still being used in Thailand.

In this study, the feasibility of biofilm processes used for decentralized greywater reclamation and reuse are discussed. Laboratory scale experiments were performed to clarify the treatability of synthetic greywater containing detergents from households including the following: (1) the degradation of detergent surfactant (MBAS and LAS); (2) the effect of aeration and HRT; (3) sludge production rate and (4) the hydrolysis of poly-p.

\section{MATERIALS AND METHODS}

Synthetic greywater The synthetic greywater was prepared by mixing three types of detergents (liquid shampoo, liquid dish washing detergent and powder laundry detergent) into tap water in consideration of various daily activities associated with modes of bathing, dish washing and laundry. The selected detergents used in this study were commercial detergents that have been widely used in household in Thailand. The quantity of the detergents added were $1.2 \mathrm{ml}$ of shampoo, $0.6 \mathrm{ml}$ of dishwashing detergent and $1.0 \mathrm{~g}$ of laundry detergent into $10 l$ of tap water. These quantities were based on reported data for detergent use ${ }^{177}$.

Reactor and operating conditions A transparent acrylic tank consisting of two chambers with a total liquid volume of $16 l$ (10 $l$ of biofilm reactor and $6 l$ of a settling chamber) was used in the experiment (Fig. 1). A plastic media plate with a volume of 4.5 $l$ and a surface area of $0.50 \mathrm{~m}^{2}$ was installed $11 \mathrm{~cm}$ from the bottom of each biofilm reactor. The media plate had been aerated in the synthetic greywater and activated sludge for three weeks for biofilm formation.

Six experiments were performed by 
a)

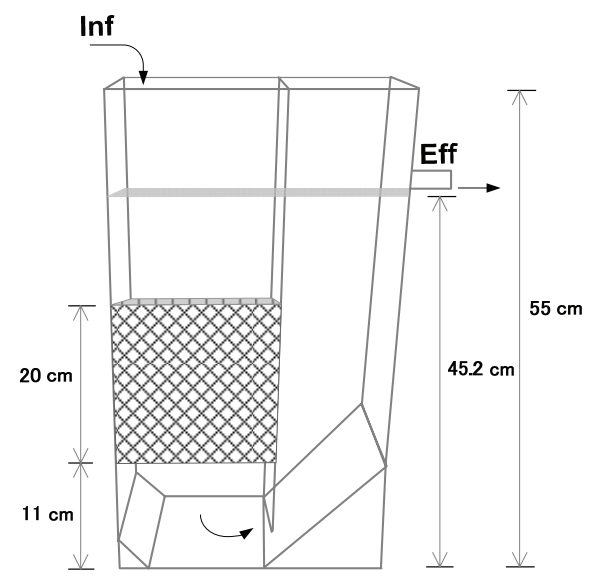

b)

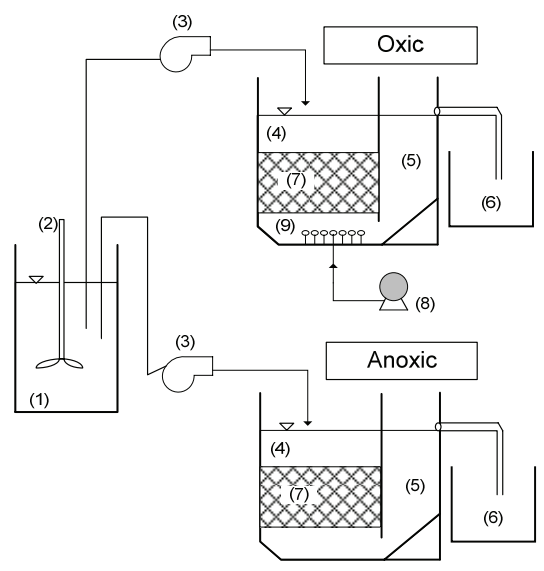

(1) feeding tank,

(2) mixer,

(3) sucking pump,

(4) biofilm reactor,

(5) settling chamber,

(6) final effluent tank,

(7) plastic media plate

(8) air blower, and

(9) air diffuser

Fig. 1 Schematic diagram of the biofilm system, a) biofilm system and b) experimental setup

changing the retention time (HRT: 1 day, 2 days and 8 days) and aeration conditions (with aeration: oxic or without aeration: anoxic). The oxic experiments with HRTs of 1 day, 2 days and 8 days are denoted as $\mathrm{O}^{-}-1$, O-2 and $\mathrm{O}^{-} 8$, respectively, while the anoxic runs with HRTs of 1 day, 2 days and 8 days are denoted as $\mathrm{A}-1, \mathrm{~A}-2$ and $\mathrm{A}-8$, respectively. The operation period for the experiments $\mathrm{O}^{-1}$ and $\mathrm{A}-1$ was 153 days. The operation period for $\mathrm{O}-2, \mathrm{O}-8, \mathrm{~A}-2$ and $\mathrm{A}-8$ was 286 days. The influent was continuously fed on the top of the biofilm reactor and flowed down through the media plate to the bottom of the reactor and then flowed through the settling chamber to be discharged. The water temperature was maintained at approximately $25{ }^{\circ} \mathrm{C}$ by using submerged heaters in the biofilm reactor during the winter season. The biofilm reactors were aerated $(0.50 \mathrm{l} / \mathrm{min})$ from the bottom of the plastic media plate in the experiments $\mathrm{O}^{-}-1, \mathrm{O}^{-} 2$ and $\mathrm{O}^{-}-8$.

Chemical analysis The influent and effluent samples were collected and analyzed twice a week. MBAS, total organic carbon (TOC), total phosphorus (TP), poly-P and $\mathrm{PO}_{4}-\mathrm{P}$ in the samples were measured using the Japanese Industrial Standards ${ }^{18)}$. The MBAS was determined using SDS as a standard. The Shimadzu TOC-VCPH/CPN analyzer was used for TOC measurements. Poly-P was estimated by calculating the difference between hydrolyzed phosphorus by hot $(1+4) \mathrm{H}_{2} \mathrm{SO}_{4}$ and $\mathrm{PO}_{4}-\mathrm{P}$. The DO, $\mathrm{pH}$ and temperature in the biofilm reactor were also measured.

Near the end of operating period of experiments $\mathrm{O}^{-}-1$ and $\mathrm{A}-1$, LAS in the influent and effluent samples were also measured as $\mathrm{C}_{10}-\mathrm{C}_{14}$ LAS (having 10 to 14 carbon atoms) by high-performance liquid chromatography (HPLC) method ${ }^{19)}$ using an ODS-80TM (Tosoh, Japan) column and a fluorescence detector (Hitachi L-7485, Japan). The eluent was a mixture of $1.5 \mathrm{mM}$ ammonium acetate in a methanol:water $(80: 20 \mathrm{v} / \mathrm{v})$ solution with a flow rate of 0.5 $\mathrm{m} l / \mathrm{min}$. A commercial mixed solution of anionic surfactants of $\mathrm{C}_{10}$ to $\mathrm{C}_{14}$ (Wako, Japan) was used as an LAS standard.

Mass balance of MBAS At the end of the each experiment, all of the sludge was collected from the biofilm reactor and the settling chamber. It was thickened by gravitational settlement for $24 \mathrm{~h}$ and subsequently mixed. A portion was removed for drying at $105{ }^{\circ} \mathrm{C}$. The accumulated sludge throughout the experiment was determined by weighing the dried sludge and dividing by the operation duration to estimate the sludge production per day. Another portion of the thickened sludge was used for MBAS content measurements. The accumulation rate of MBAS was obtained by multiplying the 
sludge production rate and the MBAS content. The degradation rate of MBAS was estimated by the difference between the input rate and the sum of the accumulation rate and the output rate.

\section{RESULTS AND DISCUSSION}

Removal of detergent surfactants The DO in the reactor remained near $8 \mathrm{mg} / \mathrm{l}$ in $\mathrm{O}^{-}-1, \mathrm{O}^{-}-2$ and $\mathrm{O}^{-}-8$ and close to $1 \mathrm{mg} / \mathrm{l}$ in $\mathrm{A}^{-} 1$, $\mathrm{A}-2$ and $\mathrm{A}-8$. The $\mathrm{pH}$ was approximately 9 in the influent and decreased slightly to $7-8$ in the reactors. The reactor $\mathrm{pH}$ was lower in $\mathrm{A}-1, \mathrm{~A}-2$ and $\mathrm{A}-8$ than in $\mathrm{O}^{-}-1, \mathrm{O}^{-} 2$ and $\mathrm{O}-8$ showing progress of anaerobic acidification in the anoxic runs. The amounts of attached biofilm gradually increased according to the progress of the operation in each experiment. Because the volume of the settling chamber was large, the effluent SS was small $(<1$ $\mathrm{mg} / l)$ in all of the experiments.

The effluent MBAS and TOC quantity fluctuated during the start-up period, then decreased in accord with the operations and finally became stable. It took approximately 130 days for the operation to stabilize for experiments $\mathrm{O}^{-}-2, \mathrm{O}^{-} 8, \mathrm{~A}^{-} 2$ and $\mathrm{A}-8$, although only 20 days of operation were sufficient in experiments $\mathrm{O}^{-}-1$ and $\mathrm{A}^{-1}$ with seeding by the micro-organism in the supernatant of previous runs $\mathrm{O}-2$ and $\mathrm{A}-2$. This result suggests that surfactant was not immediately biodegraded without seeding in greywater consisting of detergents. It took several months to accumulate enough biomass that could degrade the surfactant and achieve a stable removal efficiency. Therefore, the reactor with biomass is an important factor for reducing the start-up period in the practical application of the treatment.

Influent and effluent MBAS and TOC concentrations are shown in Table 1. The effluent concentrations reported in the table are the average values and the standard deviations that were obtained during the stable phase of $20^{-146}$ days (runs $\mathrm{O}^{-1}$ and A-1) and 144-280 days (runs $\mathrm{O}^{-}-2, \mathrm{O}^{-}-8, \mathrm{~A}^{-} 2$ and A-8). It was clear that the effluent concentrations were lower in the oxic runs than anoxic runs and decreased according to the increase of the HRT in the MBAS and TOC. The removal efficiencies of MBAS and TOC are shown in Fig. 2. The MBAS removal was greater than $90 \%$ in all of the oxic

Table 1 Influent and effluent qualities of experimental biofilm systems

\begin{tabular}{lccccccc}
\hline \multirow{2}{*}{$\begin{array}{l}\text { Parameter } \\
(\mathrm{mg} / l)\end{array}$} & Influent $^{\mathrm{a}}$ & \multicolumn{7}{c}{ Effluent $^{\mathrm{b}}$} \\
\cline { 3 - 8 } & & $\mathrm{O}-1$ & $\mathrm{O}-2$ & $\mathrm{O}-8$ & $\mathrm{~A}-1$ & $\mathrm{~A}-2$ & $\mathrm{~A}-8$ \\
\hline MBAS & $33.9 \pm 3.9$ & $3.1 \pm 0.7$ & $3.2 \pm 1.8$ & $0.9 \pm 1.0$ & $18.9 \pm 2.3$ & $12.4 \pm 3.6$ & $2.4 \pm 1.9$ \\
TOC & $27.7 \pm 2.9$ & $10.3 \pm 2.4$ & $9.2 \pm 2.5$ & $5.2 \pm 1.3$ & $18.9 \pm 2.0$ & $15.4 \pm 1.4$ & $7.1 \pm 2.6$ \\
TP & $7.3 \pm 0.5$ & $7.2 \pm 0.3$ & $7.4 \pm 0.7$ & $8.1 \pm 0.5$ & $7.2 \pm 0.4$ & $7.2 \pm 0.7$ & $7.2 \pm 0.9$ \\
poly-P & $6.3 \pm 0.9$ & $2.8 \pm 2.6$ & $1.9 \pm 1.3$ & $0.03 \pm 0.16$ & $2.0 \pm 1.5$ & $0.05 \pm 0.10$ & $0.1 \pm 0.3$ \\
$\mathrm{PO}_{4}-\mathrm{P}$ & $0.2 \pm 0.2$ & $4.0 \pm 2.7$ & $5.0 \pm 1.1$ & $7.9 \pm 0.4$ & $4.6 \pm 1.4$ & $6.7 \pm 0.9$ & $6.6 \pm 0.4$ \\
\hline
\end{tabular}

${ }^{\mathrm{a}}$ Data based on 76 samples.

${ }^{\mathrm{b}}$ Data based on $30-40$ samples.

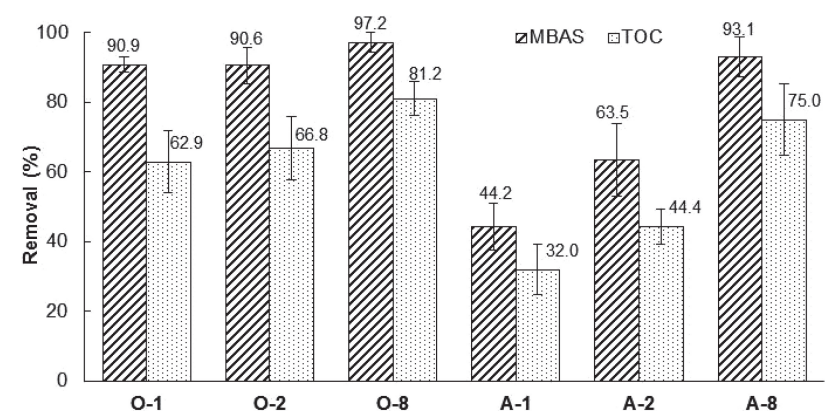

Fig. 2 Averaged percentages of MBAS and TOC removals in biofilm systems during steady state 
experiments. However, among the anoxic experiments, the MBAS removal was greater than $90 \%$ only in A-8. The removal efficiency of MBAS was considerably lower and inadequate in runs $\mathrm{A}^{-1}$ and $\mathrm{A}-2$. These results indicate that a retention time of 8 days is necessary to achieve $90 \%$ removal in anoxic conditions. Conversely, a retention time of 1 day is sufficient under oxic conditions. The significant difference in MBAS removals between the oxic and anoxic runs was recognized in the all HRT operations $(p<0.05)$. The TOC removals were also higher in the oxic experiments than the anoxic experiments although the removal efficiencies for TOC were rather low compared to the removal of MBAS.

While foaming was observed in the influent preparation, the effluents were not foaming in oxic experiments. A significant amount of foam was produced when the effluent of A-1 and A-2 were agitated. This observation clearly indicates that some surfactant remained in the effluent streams under anoxic condition, but oxic conditions provided a high removal efficiency.

Degradation of LAS homologues The influent and effluent molar concentrations of MBAS and LAS $\left(\mathrm{C}_{10}-\mathrm{C}_{13}\right)$ in the experiments
$\mathrm{O}^{-1}$ and $\mathrm{A}^{-1}$ are shown in Table 2. The difference between MBAS and LAS (sum of $\mathrm{C}_{10}-\mathrm{C}_{13}$ ) was described as LS that seemed to be anion surfactants not containing a benzene ring such as lauryl sulfate salt. The influent molar concentration of LAS was close to that of LS. The molar ratio of $\mathrm{C}_{10}: \mathrm{C}_{11}: \mathrm{C}_{12}: \mathrm{C}_{13}$ was 15: 38: 31:16. Thus, $\mathrm{C}_{11}$ and $\mathrm{C}_{12}$ were present in the influent at higher concentrations than $\mathrm{C}_{10}$ and $\mathrm{C}_{13}$. LAS and LS concentrations decreased to 5.0 and $6.1 \mu \mathrm{mol} / l$, respectively, in the $\mathrm{O}^{-}-1$ effluent and 33.1 and $34.4 \mu \mathrm{mol} / l$. respectively, in the $\mathrm{A}-1$ effluent.

The removals efficiencies for MBAS, $\mathrm{C}_{10}-$ $\mathrm{C}_{13}$, LAS (Sum) and LS are shown in Fig. 3. The LAS and LS removals in $\mathrm{O}^{-1}$ were greater than $90 \%$ but less than $50 \%$ in $\mathrm{A}-1$. The removal efficiencies of $\mathrm{C}_{10}-\mathrm{C}_{13}$ were $77.5-94.2 \%$ in $\mathrm{O}^{-1}$ and $27.9-52.7 \%$ in $\mathrm{A}-2$. The removal efficiency was greater for LAS compounds that contained more carbon atoms. These results are similar to a study published by Perales et al. ${ }^{20)}$. The study suggested that a contact aeration biofilm system can effectively decrease the toxicity caused by LAS in greywater. Although LAS $\left(\mathrm{C}_{10}-\mathrm{C}_{13}\right)$ was not measured in the experiments with retention times of 2 and 8 days, it would be removed at higher

Table 2 Molar concentrations of detergent surfactants in a unit of $\mu \mathrm{mol} / /$

\begin{tabular}{cccccccc}
\hline & \multirow{2}{*}{ MBAS } & \multicolumn{5}{c}{ LAS } & LS \\
\cline { 3 - 6 } & & $\mathrm{C}_{10}$ & $\mathrm{C}_{11}$ & $\mathrm{C}_{12}$ & $\mathrm{C}_{13}$ & Sum & \\
\hline Influent & $115 \pm 16$ & $7.9 \pm 1.2$ & $20.2 \pm 2.4$ & $16.3 \pm 2.0$ & $8.6 \pm 1.6$ & $53.0 \pm 6.9$ & $62.1 \pm 6.1$ \\
\hline Effluent & & & & & & & \\
O-1 & $11.1 \pm 2.4$ & $1.8 \pm 0.5$ & $1.7 \pm 0.1$ & $0.9 \pm 0.4$ & $0.6 \pm 0.3$ & $5.0 \pm 0.3$ & $6.1 \pm 2.2$ \\
A-1 & $67.5 \pm 5.8$ & $5.7 \pm 0.5$ & $13.5 \pm 1.9$ & $9.9 \pm 1.9$ & $4.1 \pm 0.8$ & $33.1 \pm 5.1$ & $34.4 \pm 2.3$ \\
\hline
\end{tabular}

Data based on 4 samples with triplicate samples.

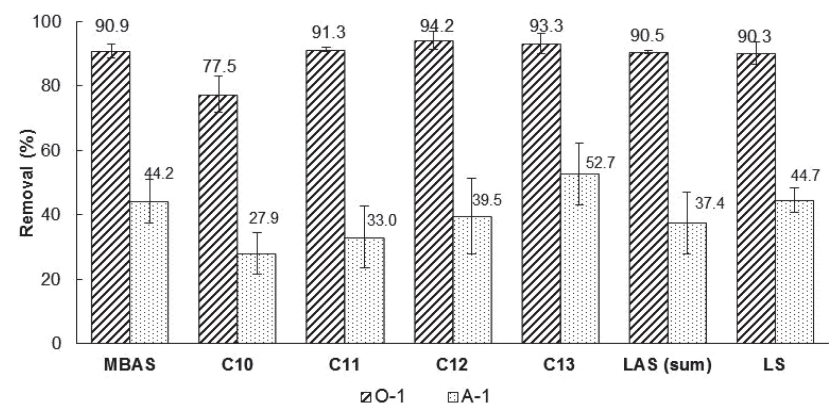

Fig. 3 Changes in averaged percentage removal of detergent surfactants in the biofilm systems 
efficiencies than the case of 1 day.

Mass balance of MBAS Sludge production rates per unit decreased TOC in each experimental run throughout the operation period are shown in Fig. 4. The production rate was higher in the experiments of HRT 8 day, especially $\mathrm{A}^{-}-1$, and almost stable in the oxic runs. The accumulation rates of MBAS were estimated to be $0.1-38 \mathrm{mg} / \mathrm{d}$ in the oxic experiments and $0.04-3.1 \mathrm{mg} / \mathrm{d}$ in the anoxic experiments. The MBAS mass balance in the stable phase (Fig. 5) was estimated by assuming that the effluent SS concentration was negligible because it was determined to be less than $1 \mathrm{mg} / l$. As shown in Fig. 5, the percentage of the accumulation in the sludge was unsubstantial except in experiment $\mathrm{O}^{-} 1$. It was suggested that the removal of MBAS was primarily caused by biological degradation. Therefore, this biofilm system would effectively remove MBAS in greywater by biodegradation.

Hydrolysis of polyphosphate The influent phosphorus was almost in the form of poly-P as shown in Table 1. According to the operation time the effluent $\mathrm{PO}_{4}-\mathrm{P}$ concentrations increased and almost all of the effluent phosphorus was $\mathrm{PO}_{4}-\mathrm{P}$ at the conclusions of the operations. It was suggested that the poly-P added to the detergents was hydrolyzed, in oxic and anoxic conditions, by phosphatase produced during the operations. However, the hydrolysis reaction was faster in anoxic conditions (Fig. 6). These results demonstrated that all of the phosphorus in the detergents was converted to $\mathrm{PO}_{4}-\mathrm{P}$ by the treatment or in the natural water source. The $\mathrm{PO}_{4}-\mathrm{P}$ accumulation may cause eutrophication in canals or estuaries. A reduction in the phosphorus content is recommended for industries, as they develop

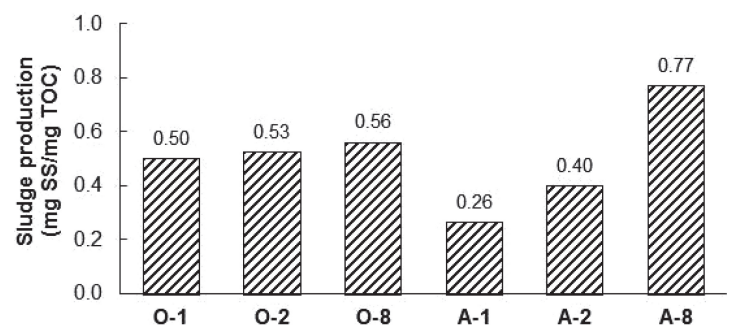

Fig. 4 Sludge production rate per unit decreased TOC in the biofilm system at different conditions

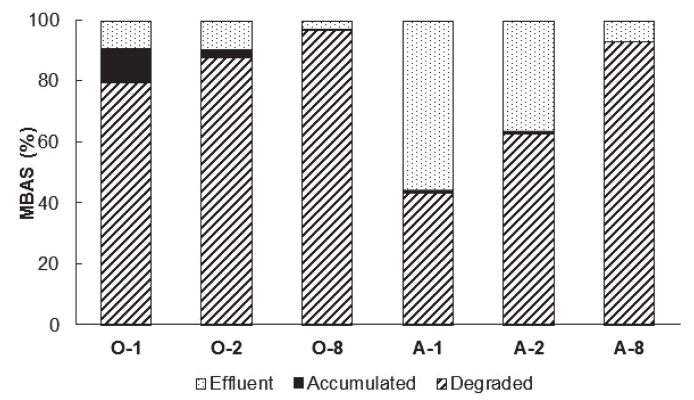

Fig. 5 MBAS mass balance in the biofilm system at different conditions
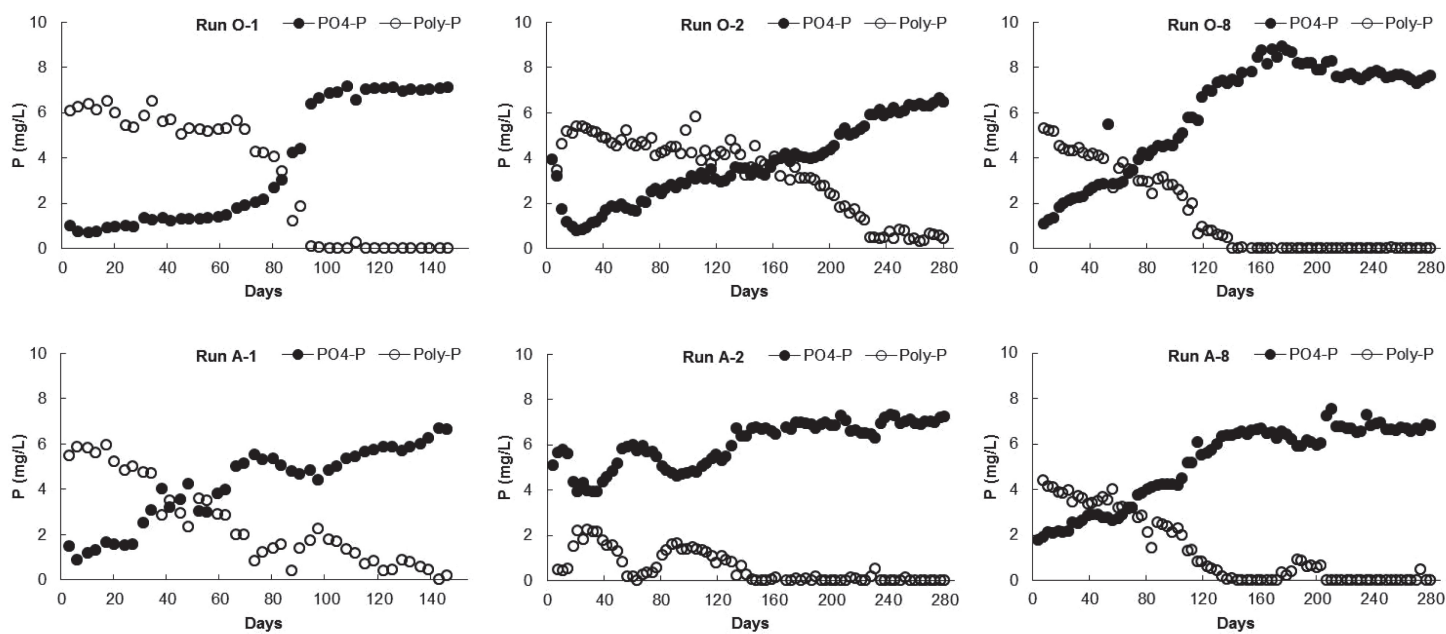

Fig. 6 Changes in $\mathrm{PO}_{4}-\mathrm{P}$ and poly-P concentrations in effluent qualities 
new detergent formulations.

Application to greywater reclamation and reuse The synthetic greywater composed of mixing three types of detergents was effectively treated, and the surfactants in the detergent were removed by oxic biofilm processes (contact aeration process) with an HRT of 1 day. The process exhibited satisfactory performance, and the absence of foaming in the effluent indicated that the detergents were effectively removed. Contact aeration seemed to be applicable to greywater reclamation and reuse. The direct nonpotable reuse of treated greywater is suitable for a range of uses, including car washing, toilet flushing and gardening purposes. Recently, decentralized package tanks using contact aeration were developed and manufactured in Thailand. The tanks seemed to be similar to Johkasou systems in Japan. These tanks would be useful not only for treatment of toilet waste but also for greywater reclamation and reuse in the periurban area of Bangkok. Although the synthetic greywater used in this study was composed by mixing three kinds of detergents and no particle matters, actual greywater contains much amount of particulate or colloidal material. Therefore the particulate or colloidal material in actual greywater seems to effect the treatment condition and deteriorate the performances. However the settled tanks put before the contact aeration in the Thailand package tanks as well as Japanese Johkasou system would partially remove such material and mitigate the effect.

\section{CONCLUSIONS}

Laboratory scale experiments treating synthetic greywater containing a mixture of three types of detergents using biofilm process under oxic and anoxic conditions showed the following results:

1) The MBAS removal was greater than $90 \%$ in all of the oxic experiments, even with an HRT of 1 day, though the removal efficiency was low in the anoxic experiments.

2) LAS and LS removals greater than 90\% were achieved in the oxic experiments with an HRT of 1 day. The removal efficiency was greater for LAS containing more carbon atoms.
3) The sludge accumulation was small, and the removal of MBAS was mainly caused by biological degradation.

4) The poly-P added in the detergents was hydrolyzed by both oxic and anoxic treatment demonstrating how these compounds contribute to eutrophication. The decrease of phosphorus content in detergent is recommended.

5) The contact aeration process seemed to be applicable to greywater reclamation and reuse in the peri-urban area of Bangkok.

\section{ACKNOWLEDGMENTS}

The authors would like to express sincere thanks to the Japan International Cooperation Agency (JICA) and the Japan Science and Technology Agency (JST) who supported this research as Science and Technology Research Partnership for Sustainable Development. The authors also thank Mr. Y. Tokuchi, Ms. S. Kanamoto, Ms. T. Matsuda and Mr. T. Yamazaki for their cooperation.

\section{REFERENCES}

1 ) Parkinson, J. and Tayler, K.: Decentralized wastewater management in peri-urban areas in low-income countries. Environment and Urbanization, 15 (1), 75 -90 (2003)

2 ) Ministry of Interior Thailand.: Ministerial Regulation No.44 (B.E.2538) issued under the Building Control Act B.E.2522 (In Thai) (1995)

3 ) Nakajima, J., Fujimura, Y., and Inamori, Y.: Performance evaluation of on-site treatment facilities for wastewater from households, hotel and restaurants. Water Science and Technology, 39 (8), 85-92 (1999)

4 ) Tokuchi, Y., Jiawkok, S., Ittisupornrat, S., Charudacha, C., and Nakajima, J.: The characteristics of greywater in a periurban area of Bangkok and its possibility for reclamation and reuse. Japanese Journal of Water Treatment Biology, Suppl. 31, 37 (2011) (in Japanese)

5 ) Imura, M., Sato, Y., Inamori, Y., and Sudo, R.: Development of a high-efficiency household biofilm reactor. Water Science and Technology, 31 (9), 163-171 (1995) 
6 ) Aqua Nishihara Corporation Limited. Bangkok, Thailand: http://www.aqua.co.th (accessed 16.02.2012) (2012)

7 ) Premier-products Company Limited. Bangkok, Thailand: http://www.premierproducts.co.th (accessed 16.02.2012) (2012)

8 ) Metcalf \& Eddy: Wastewater Engineering: Treatment and Reuse, 4th Editions. McGraw-Hill, United States of America (2004)

9 ) Venhuis, S.H. and Mehrvar, M.: Health effects, environmental impacts, and photochemical degradation of selected surfactants in water. International Journal of Photoenergy, 6 (3), 115-125 (2004)

10) Sirisattha, S., Momose, Y., Kitagawa, E., and Iwahashi, H.: Toxicity of anionic detergents determined by Saccharomyces cerevisiae microarray analysis. Water Research, 38 (1), 61-70 (2004)

11) Ni, HG., Lu, FH., Wang, JZ., Guan, YF., Luo, XL., And Zeng, E. Y.: Linear alkylbenzenes in riverine runoff of the Pearl River Delta (China) and their application as anthropogenic molecular markers in coastal environments. Environmental Pollution, 154 (2), 348-35 (2008)

12) Moreno-Garrido, I., Hampel, M., Lubián, L.M., and Blasco, J.: Marine microalgae toxicity test for linear alkylbenzene sulfonate (LAS) and alkylphenol ethoxylate (APEO). Fresenius Journal of Analytical Chemistry, 371 (4), 474-478 (2001)

13) Terzic, S. and Ahel, M.: Input and behaviour of linear alkylbenzenesulphonates (LAS) in a stratified estuary. Marine Pollution
Bulletin, 28 (12), 735-740 (1994)

14) Kikuchi, M. et al.: The distribution and fate of major surfactants in some river waters in Tokyo. Japan Journal of Water Pollution Research, 11 (4), 248-256 (1988) (in Japanese)

15) Halliwell, D., MCKELVIE, I. D., Hart, B. T., and DUNHILL, R. H.: Hydrolysis of triphosphate from detergents in a rural waste water system. Water Research, 35 (2), 448-454 (2001)

16) Reynolds, C. S.: The ecology of freshwater phytoplankton. Cambridge University Press, Cambridge, pp. 384(1984)

17) Fujimura, Y., Ogura, H., and Kobayashi, S.: Several pollution control effects of some measures for domestic effluent in house hold. Journal of Environmental Laboratories Association, 22 (1), 25-31 (1997) (in Japanese)

18) Japanese Industrial Standards Committee: JIS K0102, Testing methods for industrial wastewater (2008)

19) Wangkarn, S., Soisungnoen, P., Rayanakorn, M., and Grudpan, K.: Determination of linear alkylbenzene sulfonates in water by liquid chromatography-UV detection and confirmation by liquid chromatography-mass spectrometry. Talanta, 67 (4), 686-695 (2005)

20) Perales, J.A., Manzano, M.A., Sales, D., and Quiroga, J.M.: Linear alkylbenzene sulphonates: biodegradability and isomeric composition. Bulletin of Environmental Contamination and Toxicology, 63 (1), 94 -100 (1999)

(Submitted 2012. 4. 19)

(Accepted 2012. 6. 29) 